\title{
473907 - INTERACTION BETWEEN ROCURONIUM POTENCY AND DURATION OF PROPOFOL-TIVA AT THE ADDUCTOR POLLICIS
}

\author{
Thomas Hemmerling, MD, Nhien Le, cand med, David Bracco, MD \\ Anesthesiology, McGill, Montreal, QC, Canada
}

Introduction: The potentiation of the potency of neuromuscular blocking agents by volatile anesthetics is well known. So far, it is mostly believed that there is no or very little potentiation of the action of neuromuscular blocking agents with intravenous anesthetic agents, such as propofol. In addition, little is known of the impact of the duration of general anesthesia on the potency or action of neuromuscular blocking agents. In a previous study, we presented an increase of mivacurium potency by 1.5 fold when administered 20 min after the beginning of TIVA propofol (1). The purpose of this study was to determine whether the potency of a steroid neuromuscular blocking agent, rocuronium, was also altered by the duration of TIVA propofol.

Methods: After Ethics committee approval, this prospective, block randomized and double-blinded study investigates a total of 30 patients, separated in 2 groups of 15 patients. The potency of rocuronium was determined after either 5 minutes of TIVA propofol (Group $5 \mathrm{~min}$ ), or after 20 minutes of TIVA propofol (Group $20 \mathrm{~min}$ ). Each patient received four doses; an initial dose of $200 \mu \mathrm{g} / \mathrm{kg}$ and three increments of 100 $\mu \mathrm{g} / \mathrm{kg}$ of rocuronium. The dose-response relation of rocuronium for the Adductor pollicis muscle (AP) was determined by using a cumulative dose-response technique (2).

Results: Preliminary results of 4 patients (Group 5 min; age 64 yrs [44, 81], weight $88 \mathrm{~kg}$ [61, 115]) and 5 patients (Group $20 \mathrm{~min}$; age 48 yrs [25, 62], weight $88 \mathrm{~kg}[82,113]$ ) are presented as median [quartile, 25th, 75th]. The potency determined as ED50 and ED95 for the AP was significantly higher after 20 min than after 5 min of propofol TIVA (Table 1).

Discussion: Preliminary results indicate a similar pattern of decrease of potency of rocuronium as described for mivacurium (1). Further studies need to focus on determining the physiological reason for this interaction between the potency of neuromuscular blocking agents and propofol.

References: 1 CAN J ANESTH 2007 54: 445822 Br J Anaesth, 76(3), 389-395 This work was supported by the 2006 BMS Career Scientist Award.

Table 1

\begin{tabular}{|c|c|c|}
\hline & $5 \min$ & $20 \min$ \\
\hline ED 50 & $277(259,282)^{*}$ & $195(90,210)$ \\
\hline ED 95 & $595(481,729)^{*}$ & $347(288,436)$ \\
\hline
\end{tabular}

Data as median (25th, 75th); * $\mathrm{P}<0.05$ 